\title{
The Problamatic Methods in Teaching of Human Anatomy and Physiology
}

\author{
*Edith María Beltrán Molina \\ Sancti Spíritus, Cuba
}

Submission: April 17, 2016; Published: September 16, 2016

*Corresponding author: Edith María Beltrán Molina, Head of the interdisciplinary group of Biology Department of Natural Sciences UNISS José Martí Pérez . Faculty of Educational Sciences, Sancti Spiritus. Cuba

\begin{abstract}
To enhance the effectiveness of teaching and learning process is necessary to change the position of Professor Respect to the direction of this. So that a process whose activity is centered on the teacher, with a strong tendency for students to learn in a reproductive, is transformed into one in which the teacher change its conception about the learner

This transformation will bring about a true student leadership in the pursuit and use of knowledge, leading to transit through different levels of demand, ranging from breeding to the application to new situations. The change to the aspiration needs of a dynamic in which the permanent stay student interaction with the learning objects.

New times demand that in the process of learning a set of methods that allow the student to be reflective, participatory, independent, questioning, with capacity to argue, determined, enterprising, with investigative spirit and in which form is used the moral values to which society aspires. Among them are those characterized by a focus problem, the latter has as its central objective problem solving. It is characterized by a teaching that makes the main emphasis on the creation of problematic situations, i.e. through problems creates the need for new knowledge that should be studied.
\end{abstract}

\section{Introduction}

This issue has been studied previously by a team of Cuban researchers from universities dissimilar Pedagogical Sciences, who refer to different subjects.

Marta Martinez Wheeler and Justo Luis Pereda address the use of methods problémicos Philosophy, Jorge Luis Hernandez Mujica and Ines Salcedo in Biology , Bernardino A. Almeida and José Tomás in mathematics, Felicia Gates and Barbara Fierro in literature, Margarita Gonzalez and Yamile Quintero in history, Juan Túrcaz and Maria del Carmen Puñales foreign language , Maria del Carmen Leon and Pablo Hernandez in the teaching of chemistry, however, have not been reported similar studies in the Anatomy discipline and Human Physiology accessed in Los problémicos teaching methods Ignacio Ramirez [1].

They have also highlighted other researchers such as Carlos Alvarez de Zayas [2], Adania Guanche Martinez [3], Luis Azcuy Lorenz [4], among others.

The essence of the methods focus problem is the contradictory nature of knowledge. The exposure problem is an exhibition "developer" than exposure, the teacher creates problematic situations, which must be transformed into teaching problems, and he exposes the dynamics of the formation and development of the concept.

In the partial search method the teacher organizes the search for the solution of the problem posed teaching: exposes the contradictory elements, not solve, but encourages independent search (as) students (as).

Another problem method is the heuristic conversation consisting of a productive dialogue that must respond to the problem posed teaching for the development of this method should be a partial search prior preparation or have previous experience.

The three problémicos methods described above form the basis of the research method, which integrates a wealth of cognitive experiences and a high degree of independence and creative activity.

For the implementation of problémicos methods should consider factors such as the specificity of the subject and the particular content in question, the level of independence achieved by students and their experience in dealing with problematic 
situations, a factor that must be analyzed not only individual but also collective level for all students in the classroom.

Although not be considered the problem-oriented approach to teaching as universal, because there are many situations that cannot be applied, it is certainly an effective way to teach and develop in the knower creative thought, belief, scientific world and generally make the entire content of its activity is aimed at pursuing and obtaining a social object.

In addressing the study of the problem-oriented approach to teaching, it is important to stop the analysis of its fundamental categories: the problem situation, the teacher problem, tasks and questions problémicas and not problémicas and problemoriented. Martinez Wheeler [5].

The categories are the instruments to develop the class teacher, are steps of knowledge; allow students to discover and learn the object of study and get to its essence; reflect the most important moments in the production process of assimilation of truth in the educational process.

\section{Disscusion}

The fundamental link to the implementation of problémicos methods is the problem situation, a category that is a bit complex to determine for the teacher, so following are examples of situations that can be used in the process of teaching and learning is of human anatomy and physiology.

a. Most mammals have a staff on his penis allowing penetration in the absence of erection; man lacks this structure, phallus, despite being a flabby body is able to penetrate into the vagina of women through the process of erection, during which grew by $30 \%$, (although there penises that can increase more) temperature rises to 36.7 degrees body and scrotum remains very tense.

b. How is it possible that the penis being a flabby body and lacking staff can stay hard and rigid during sexual intercourse? What the tension of the scrotum is?

c. The heart is a muscle about the size of the fist of each person, inside which passes the blood, which circulates throughout the body, because its mission is to pump the fluid. How is it possible that the heart being so small to pump blood to all parts of the body?

d. Many people think that eating is a pleasure; however, this may bring food imbalances causing cardiovascular disease, cancer, high blood pressure, anemia, diabetes mellitus, osteoporosis, obesity, among others. Why do people think that eating is a pleasure as this is the first premise to maintain health and life?

e. In the human body the digestive system plays an important role in providing water, electrolytes and food substances continuously, which achieved mechanical and chemical processing of food eaten, these occur first in the oral cavity allowing the formation of mush able to pass through a tube $38 \mathrm{~cm}$, terraced walls, this would be difficult if continued solid food. How ingested food can become mush able to pass through a body attached without damaging walls, mechanical character structures which allow and what chemical reactions occur?

f. The stomach is an organ storage of food and can expand holding a volume of up to 2 liters of 3 to 5 hours approximately, is structured in accordance with their main function is the chemical preparation of food in the presence of an acid very strong capable of corroding and even dissolve metals such as iron. How the stomach being so small you can retain that amount of food many hours and not be damaged by the action of acid secreted irritating? What is the chemical processing of food?

g. The liver is an organ or viscera present in vertebrates and some other animals; and it is, in turn, bulkier gland anatomy and one of the most important concerning the metabolic activity of the organism. Plays unique and vital functions, however according to the World Health Organization in total approximately 27,000 people die annually from liver cirrhosis caused mainly by excessive consumption of alcohol. If everyone knows the importance of the liver for the proper functioning of the human organism, then decrease alcoholisms rates and therefore reduce deaths by alcoholic cirrhosis.

h. The airways have devices that condition the inspired air quality to reach the lungs, however, cigarette smoke contains toxic particles passing through these affect their performance why cigarette smoke passing by airway it remains irritating if these bodies have devices responsible for air conditioning? From these situations the teacher prepares tasks and problem question and not problémicas that the student solves independently or jointly teacherstudent, to give the solution to the teacher problem.

\section{Conclusion}

The focus problem is a fundamental requirement to take into account when designing the teaching-learning process to contribute to its improvement and form education professionals with a solid foundation of knowledge, skills and habits. Problem situations designed allow the use of problémicos methods in the teaching of Human Anatomy and Physiology; these stimulate productive activity, i.e. reflection, creation, independence, the search for new knowledge and tend intellectual development and values.

\section{References}

1. Ramirez Ignacio Gonzalez Margarita (2006) The problémicos teaching methods. Editorial, San Marcos, USA.

2. Alvarez de Zayas C (1995) School in life. Editorial Pueblo and Education, Havana, Cuba, pp. 21-115. 
3. Guanche Martinez A (1997) Teach Natural Sciences for teaching problem: an effective solution. School Challenge 1(9).

4. Azcuy Lorenz L (2004) Some theoretical considerations about the Teaching problemic. Rev Hum Med 4 (1).
5. Martinez Wheeler M (1987) Teaching problem of Marxist Leninist philosophy. Editorial Social Sciences, Havana, Cuba, pp. 125-206. 